\title{
A Biomass Index for Northern Shrimp (Pandalus borealis) in Davis Strait Based on Multiplicative Modelling of Commercial Catch-per-unit-effort Data (1976-97)
}

\author{
C. Hvingel \\ Pinngortitaleriffik-Greenland Institute of Natural Resources \\ P. O. Box 570, DK-3900 Nuuk, Greenland \\ H. Lassen \\ Danish Institute for Fisheries Research \\ Charlottenlund Slot, DK-2920 Charlottenlund, Denmark \\ and \\ D. G. Parsons \\ Science Branch, Department of Fisheries and Oceans \\ P. O. Box 5667, St. John's, Newfoundland, Canada A1C 5X1
}

\begin{abstract}
Four biomass indices for the northern shrimp (Pandalus borealis) stock in Davis Strait, derived from commercial catch-per-unit-effort (CPUE) data, were analysed by multiple regression to construct a single time series with the ultimate goal of tracking trends in stock biomass during the period 1976 to 1997. Indices from the offshore fisheries have been used previously in stock assessments while an index derived from logbook data for small inshore vessels operating around Disko Island has not been presented previously.

The analysis used multiplicative models and linked catch rate to vessel fishing power, temporal and spatial availability and overall annual biomass density. In two of the indices, the temporal (MONTH) and spatial (AREA) effects were modelled as interaction terms. Other second order effects were treated as random error. The AREA*MONTH interaction term corresponds to an annual migration or behavioural pattern. The procedure corrects for increases in technological efficiency over the 22-year period due to fleet renewal but changes in the efficiency of individual vessels were not accounted for.
\end{abstract}

The four indices were combined, weighted by the area of the total fishing grounds each index represented. The combined index was indicative of the biomass density for shrimp greater than about $17 \mathrm{~mm}$ in carapace length. During the $1976-88$ period, the index was higher than from 1989 onwards. The combined index showed agreement with research survey biomass estimates but the contrast in the data was low during the period of comparison (1988-97). The combined CPUE index was applied to the total catches to derive estimates of total standardized effort. This effort index increased substantially in the late-1980s.

Key words: biomass, CPUE index, Davis Strait, multiplicative models, shrimp, West Greenland

\section{Introduction}

Catch and effort data from commercial fishing vessels provide simple but important statistics in fisheries management. They are frequently used directly to provide annual indices of stock biomass and in tuning of Virtual Population Analyses (Anon., 1997). Catch-per-unit-effort (CPUE) data are influenced by several factors, including availability of target species, vessel fishing power and 
annual, seasonal and areal variation in biomass. Therefore, methods for correcting CPUE data for effects other than annual biomass changes must be applied before using them as biomass indices.

Standardizing CPUE data to improve their relation to stock biomass density has been approached in different ways (Gulland, 1956; Beverton and Holt, 1957). Gavaris (1980) and Kimura (1981) described a now widely used method based on the work of Gulland (1956) and Robson (1966) using multiplicative models. The use of CPUE indices as biomass indicators depends critically on standardisation, especially of fleet efficiency. Pascoe and Robinson (1996) reviewed implications of efficiency increase and methods of quantification.

CPUE standardisation by multiplicative modelling has recently been used for southern red snapper, Lutjanus purpureus (Perodou and Prevost, 1989; Perodou, 1994); ice-fish, Champsochephalus gunnari (Gasiukov, 1991); sole, Solea solea (Large, 1992); Atlantic swordfish, Xiphias gladius (Miyaki, 1989; Hoey et al. 1995). Within the Northwest Atlantic Fisheries Organization (NAFO), multiplicative models are frequently used to calculate commercial CPUE-based biomass indices to trace annual fluctuations in stocks, e.g. in the assessment of redfish (Sebastes spp.), silver hake (Merluccius bilinearis), Greenland halibut (Reinhardtius hippoglossoides) and northern shrimp (Pandalus borealis) (Anon., 1997).

The northern shrimp (Pandalus borealis) stock in Davis Strait occurs in NAFO Divs. 0A and $1 \mathrm{~A}-1 \mathrm{~F}$, primarily in depths between 150 and $600 \mathrm{~m}$ (Fig. 1). The fishery for shrimp started in inshore areas during the late-1930s. The offshore fishery began as a multinational fishery around 1970. Since the first assessment of the stock in 1976, catch-rate indices have been used as indicators of the status of the stock. Until 1989, an index from the Greenland fishery based upon seven trawlers was used (Carlsson, MS 1985). This index was a simple average of CPUE data by haul covering Div. 1B in which most of the fishery took place at the time. A revised version of this index based on a multiplicative model was introduced in 1990 (Lassen and Carlsson, MS 1990).

Based on a new logbook system introduced in 1985 a new standardized index for Div. 1B has been calculated (Carlsson and Lassen MS, 1991). This index included only shrimp larger than approximately $8 \mathrm{~g}$ for which discard is normally negligible (Lehmann and Degel, MS 1991) and thus avoided the influence of variations in unreported discard. A parallel index for Div. 1CD has been calculated since 1993 as the fishery had expanded to these areas during the late-1980s (Carlsson et al., MS 1993; Siegstad et al., MS 1995). CPUE data from logbooks from Canadian vessels fishing in Div. OA were also used to construct a standardized index (Parsons and Veitch, MS 1991 and MS 1995).

In this paper the standardized CPUE indices for Div. 1B, 1CD and 0A are re-analysed and an additional new "inshore" index constructed. The purpose of our analyses was to combine these temporally and geographically fragmented indices into a single time series of standardized commercial CPUE data for northern shrimp in Davis Strait from 1976 to 1997 . This series is discussed as a possible indicator of changes in stock biomass over the same period.

\section{Material and Methods}

\section{Theory, assumptions and problems of design}

We derived standardized indices separately for each area using multiplicative models, which included the following variables: (1) individual vessel fishing power, (2) seasonal availability of shrimp, (3) spatial availability of shrimp and (4) annual mean CPUE. The analysis is based on an approach similar to that presented by Large (1992) and based on the theory described in Richards and Schnute (1992). The input data were mean CPUE by vessel, area, month and year. The calculations were done using the SAS statistical software (Anon., 1988). The multiplicative model was represented in logarithmic form:

$$
\begin{aligned}
& \ln \left(C P U E_{i j k l}\right)=\ln (u)+\ln \left(A_{i}\right)+\ln \left(S_{j}\right) \\
& +\ln \left(V_{k}\right)+\ln \left(Y_{l}\right)+e_{i j k l}
\end{aligned}
$$

(Model 1)

where $C P U E_{i j k l}$ is the mean CPUE for vessel $k$, fishing in area $i$ in month $j$ during year $l(k=1, \ldots, \mathrm{n} ; i=$ $1, \ldots, \mathrm{a} ; j=1, \ldots, s ; l=1, \ldots, y) ; \ln (u)$ is overall mean $\ln (C P U E) ; A_{i}$ is effect of the $i^{t h}$ area; $S_{j}$ is the effect of the $j^{\text {th }}$ month; $V_{k}$ is the effect of the $k^{\text {th }}$ vessel; $Y_{l}$ is the effect of the $l^{\text {th }}$ year; $e_{i j k l}$ is the error term assumed to be normally distributed $N\left(0, \sigma^{2} / n\right)$ where $n$ is the number of observations in the cell and $\sigma^{2}$ is the variance. The standardized CPUE indices are the antilog of the year coefficient. 
The data sets are unbalanced, with a range of 0 to 784 hours of effort per cell. Up to about $80 \%$ of the cells were empty. Parameter estimates of the vessel, month and area variable from a first run of Model 1 were compared. Levels within each variable were combined in subsequent analyses if the parameter estimates were within the distance of one mean standard error. This reduced the number of empty cells to $40-60 \%$ and resulted in a mean effort of about 500 hours per non-empty cell.

The model is based on the following assumptions:

- The fishing power of each vessel is constant over time and space (i.e. it does not vary by season, year or area).

- The geographical distribution of the stock is constant over seasons and years.

- Seasonal availability varies in a constant pattern among years (i.e. periods of high and low availability occur at approximately the same time each year).

The validity of these assumptions was evaluated for each index series and investigated by studying 2-way interactions among vessel, area, month and year. Higher order interactions were not investigated because of the occurrence of many empty cells.

The large sample size introduced a problem of excessive statistical power, so that some interactions with little explanatory value had quite high statistical significance. Interactions, although statistically significant in a full model including all second order effects were ignored without further investigation if they did not plausibly correspond to physical reality as we see it in the fishery and at the same time explained little of the variation in the data. This approach meant omitting the VESSEL interactions with AREA and MONTH in the investigative model including second order effects:

$\ln \left(C P U E_{i j k l}\right)=$ Model $1+\ln \left(A_{i} * S_{j}\right)$ $+\ldots \ldots .+\ln \left(V_{k} * Y_{i}\right)+e_{i j k l}$

(Model 2)

This was done to obtain more powerful tests of the retained effects. Significant interactions in Model 2 were further investigated to see if they showed a systematic pattern between years, months and areas.

\section{Construction of the four individual CPUE indices}

Catch and effort statistics for the shrimp fishery in Davis Strait (Div. 0A and 1A-F) are collected on a haul-by-haul basis through logbooks. Data items available are: date, time, geographical position, depth, tow duration and catch $(\mathrm{kg})$ either by size group or total catch. The CPUE data are total catch $(\mathrm{kg})$ per hour trawling.

For Subarea 1 Greenlandic logbooks are available since 1976 but only for a smaller part of the fishery. With the introduction of a new Greenlandic logbook in 1985, data now account for about $99 \%$ of the catches by the offshore fleet component (>80 GRT) and about $50 \%$ of the catches taken by the inshore fleet $(<80$ GRT). The Canadian logbook system has covered the Canadian shrimp fishery in the Davis Strait from the beginning of the fishery in 1979. Since 1981 Canadian shrimp fishing activity has been restricted to Div. 0A in an area extending from about $67^{\circ}$ to $69^{\circ} \mathrm{N}$ and $58^{\circ}$ to $60^{\circ} \mathrm{W}$. This fishery thus covers the part of the stock area in the Canadian zone only (Fig. 1).

The fishery was mainly restricted to the shrimp grounds in Div. 0A and 1B up to the mid-1980s. Thereafter, the fishery gradually expanded southwards to Div. 1C and 1D. There are limited data reported from Div. 1A west of $56^{\circ} \mathrm{W}$ and some of these are actually misreported catches from Div. 1B and possibly even further south. Therefore, data referring to Div. 1 A west of $56^{\circ}$ have been omitted from the analysis. Except for in recent years little effort is spent in Div. 1E and 1F, so data from these areas were excluded from the analysis as well.

The data are supplied by four different fleets largely fishing in different areas and over different periods (Table 1). We therefore developed separate indices by fleet which meant keeping the former Div. 0A and KGH (Kongelige Grønlandske Handel trawlers) indices as individual units, calculating a new "inshore" index and, combining the data for the former Div. 1B and Div. 1CD indices into a "1BCD" index. The main criterion for including an individual vessel in either of the multiplicative models was three years of participation in the fishery covered by the index. Hauls by twin-trawls (two complete trawls towed simultaneously) were excluded from the analysis. The area definition used is based on distinct fishing grounds. 


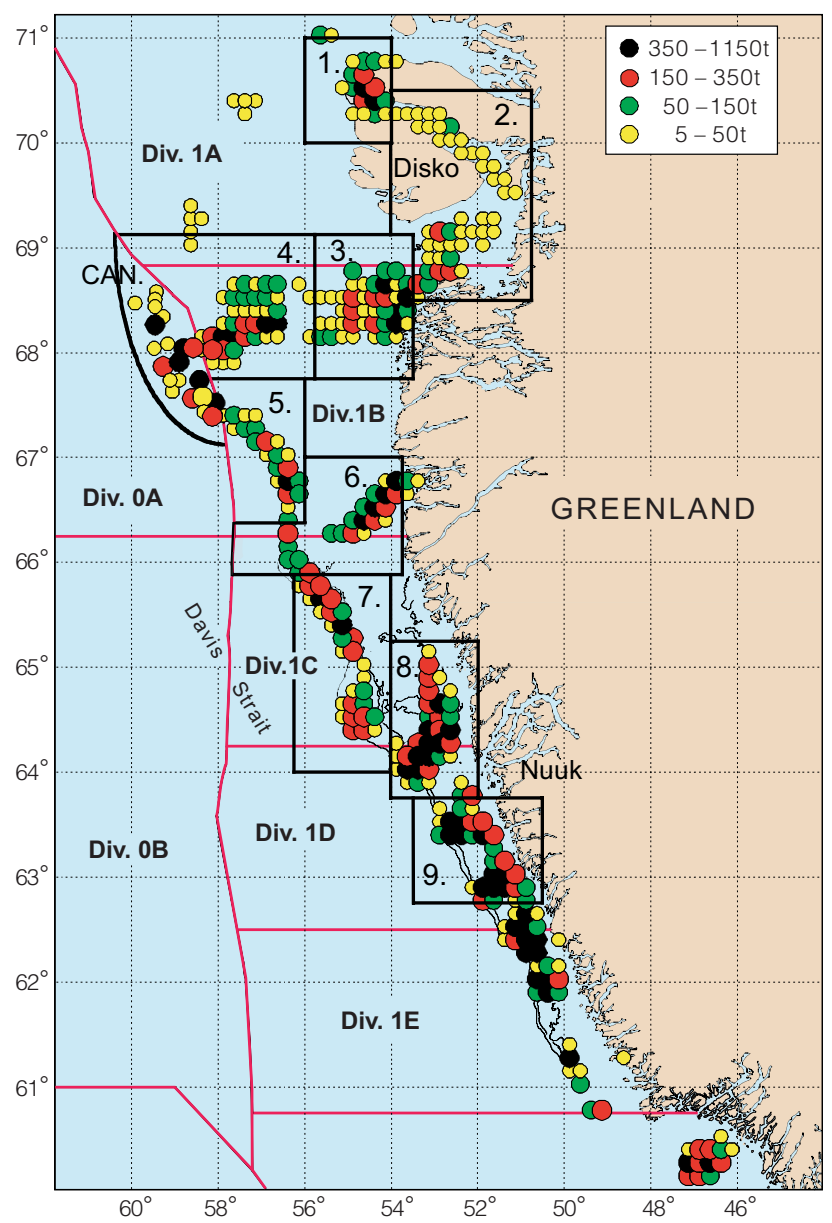

Fig. 1. Distribution of shrimp catches in the Davis Strait in 1995 by $7.5^{\prime} \times 15^{\prime}$. The areas used as levels of the AREA variable in the multiplicative models for standardizing commercial catch-rates are overlaid. Areas 1-3 are included in the inshore index; Areas 3-6 in the $\mathrm{KGH}$ index; Areas 4-9 in the $1 \mathrm{BCD}$ index and $\mathrm{CAN}$ in the $0 \mathrm{~A}$ index.

The 1BCD index, 1987-97. The CPUE data for the $1 \mathrm{BCD}$ index were grouped into six areas (Areas 4-9, Fig. 1) which largely cover Div. 1B, 1C and 1D. In 1987-88 the fishery in Div. 1C and $1 \mathrm{D}$ was still in its infancy and the few exploratory hauls from Areas 7-9 in 1987 and Areas 8-9 in 1988 were therefore omitted from the calculations.

Thirty-two of 64 vessels larger than 80 GRT met the criteria for inclusion in the analysis. Based on the exploratory run of the main effects model (Model 1) the vessel effect was collapsed into 16 groups consisting of 1-5 vessels with similar fishing power. The month effect was reduced to 7 levels by grouping months with similar indices of rela- tive shrimp availability. Areas 4, 6, 7, 8 and 9 were combined into one level (see Table 1).

The KGH index, 1976-90. The initial offshore fishery was executed by 7 sister trawlers (800 GRT) all operated by the Kongelige Grønlandske Handel $(\mathrm{KGH})$. Even though other vessels joined the fishery between 1976 and 1987, the logbook information was only reliable for the KGH trawlers before 1987 (Lassen and Carlsson, MS 1990). Therefore this time series was treated separately and only data for these 7 vessels were included in the analysis. The early fishery only covered Div. $1 \mathrm{~B}$ and the index is restricted to this area. Thus data from Areas 3, 4, 5 and 6 (Fig. 1) were considered for this index. 
TABLE 1. Coverage in time (years) and space (NAFO Divisions) and vessel size (GRT) of the four fragmented CPUE indices and number of variable levels and empty cells in the corresponding multiplicative models. Numbers in parentheses are before grouping of similar variable levels (see text).

\begin{tabular}{|c|c|c|c|c|c|c|c|c|}
\hline \multirow[b]{2}{*}{ Index } & \multicolumn{3}{|c|}{ Coverage } & \multicolumn{4}{|c|}{ Class variable (No. of levels) } & \multirow{2}{*}{$\begin{array}{c}\% \text { cells } \\
\text { Empty }\end{array}$} \\
\hline & Year & NAFO Division & Vessel GRT & Year & Season & Area & Vessel & \\
\hline IBCD & $1987-97$ & Div. 1BCD (offshore) & $80-2500$ & 11 & $7(12)$ & $2(6)$ & $16(32)$ & $50(76)$ \\
\hline $\mathrm{KGH}$ & $1976-90$ & Div. 1B (offshore) & 800 & 15 & $10(12)$ & $2(4)$ & $2(7)$ & $37(73)$ \\
\hline $0 \mathrm{~A}$ & $1981-96$ & Div. 0A (offshore) & $500-4000$ & 16 & $2(5)$ & 1 & $10(29)$ & $62(78)$ \\
\hline Inshore & $1988-97$ & Div. 1AB (Disko area) & $50-80$ & 10 & $5 \quad(9)$ & $3(3)$ & $10(18)$ & $49(62)$ \\
\hline
\end{tabular}

The analyses for reducing variable levels showed that 6 of the seven vessels could be treated as a group in the subsequent analyses. The month variable could be reduced to 10 levels and Area to 4, 5 and 6 combined (Table 1).

The 0A index, 1981-96. The fishery in Div. $0 \mathrm{~A}$ takes place in a very limited area (Fig. 1) thus no areal segregation was required for the $0 \mathrm{~A}$ index. A total of 48 vessels were represented in this data base but only 29 had operated in the area for at least three years and were therefore included in the analysis. Although the fishery takes place in JuneDecember, the analysis was confined to JulyNovember because effort was sparse in June and December, especially in recent years. Effort in 1997 was low and an unknown proportion was due to twin trawling, thus 1997 was not included.

The 29 levels of the vessel variable were reduced to 10 consisting of 1-7 individual vessels of similar fishing power. The months AugustNovember were grouped into one level before subsequent analyses.

The inshore index, 1988-97. The inshore shrimp fishery in Greenlandic waters is almost exclusively confined to areas around Disko Island in Div. $1 \mathrm{~A}$ and $1 \mathrm{~B}$. This fishery is restricted to vessels below 80 GRT and has in recent years accounted for about $20-25 \%$ of the total catches in Subareas $0+1$. No standardized index has previously been presented for this fishery.

The areas included in the index were those shown as Areas 1, 2 and 3 in Fig. 1. Comprehensive data were available since 1988 and 28 vessels are represented. The fishery occurs from March/ April to December. Eight vessels were excluded as they fished irregularly in the area. The vessel variable was further reduced to 10 levels consisting of groupings of 1-3 vessels due to similarity of estimated fishing power. The month variable was reduced from 9 to 5 levels.

\section{Construction of the 1976-97 time series}

A single combined index of the development of the population biomass was derived by aggregating the four available indices. This was done using a least squares method. The individual CPUE series for the $i^{\text {th }}$ fleet, $\mu_{i j}$, was assumed to reflect an overall biomass series, $Y_{j}$, and a constant fleet coefficient, $v_{i}$, so that $\mu_{i j}=v_{\mathrm{i}} Y_{j}+e_{i j}$. The error, $e_{i j}$, was considered to be distributed with mean zero and variance $\sigma_{i}{ }^{2}$. For the purpose of fitting we assumed that $e_{i j}$, had variances inversely proportional to the area of fishing ground, $a_{i}$, covered by fleet $i$. The factor, $a_{i}$, was taken to be the area of sea bottom between 150-600 m. Hence, the combined index could be constructed by fitting $v_{i}$ and $Y_{j}$ to minimize a weighted sum of squares:

$$
\sum_{i} a_{i} \sum_{j}\left(\mu_{i j}-v_{i} Y_{j}\right)^{2}
$$

The area weighting factor, $a_{i}$, for the $1 \mathrm{BCD}$, $\mathrm{KGH}, 0 \mathrm{~A}$ and inshore indices was calculated to $0.46,0.36,0.05$ and 0.13 , respectively.

We used a standard jackknife (Efron, 1982) to examine possible error in the resulting estimates and to calculate estimates of the standard error. The jackknife data set was created by a repeating procedure of running Model 3 (see below) to get annual indices for the individual CPUE time series and fitting them by the method described above to get the combined index, leaving out one year of data at a time. The jackknife estimate of standard error is defined by:

$$
s \hat{e}=\left[\frac{n-1}{n} \sum\left(Y_{j}^{\prime}-\bar{Y}^{\prime}\right)^{2}\right]^{1 / 2}
$$


where $Y_{j}^{\prime}$ is the estimate obtained with the $j^{\text {th }}$ year of data deleted, $\bar{Y}$ is the arithmetic mean of the $Y_{j}^{\prime} s$ and $n$ is the number of years of data included.

\section{Results}

\section{The 1BCD index}

The assumptions of constant distributional and seasonal patterns were investigated by running Model 2. The ANOVA scheme of this model applied to the Div. 1BCD data show that all effects were significant at a $1 \%$ level (Table 2). Cook's D influence statistic (Anon., 1988) indicated that the model was not driven by a few highly influential points. Plotting the studentdized residuals did not reveal any trend with either the predicted CPUE or with the main effects and the plot suggested constant variance of the errors. A normal probability plot indicated that errors were normally distributed.

The YEAR*MONTH effect represents seasonal changes in availability of shrimp to the trawl between years and was the most significant of the interactions including YEAR (Table 2). A plot of YEAR*MONTH effect against time suggests that the seasonality varied between years in the period 1985-93 but this variability has been much less pronounced in recent years. A similar analysis for individual areas gave the same conclusion. Inspection of the overall time trend obtained by the two models (Models 1 and 2) did not indicate major differences but the variation between years in the YEAR effect from Model 2 was higher. This however could indicate that the estimates from Model 2 are not quite stable. It was concluded that the bias caused by ignoring the YEAR*MONTH interaction has little effect on the time series.

The YEAR*AREA effect represents differences in the geographical distribution between years. A plot of YEAR*AREA effect against time suggests that the significance of the interaction is driven by an abnormal year 1995. All other years do not seem to deviate from each another. We therefore included the effect in the random error together with the YEAR*VESSEL term which has minor explanatory value of the data but indicates the problem of the continuing effect of improved fishing power.

The MONTH*AREA interaction suggests the existence of an areal difference in seasonality that was found to be consistent between years. This could reflect an annual migratory or behavioural pattern. This was the interaction with the highest mean square contribution. The final model therefore included the MONTH*AREA interaction along with the YEAR and VESSEL main effects:

$$
\begin{aligned}
& \ln \left(C P U E_{i j k l}\right)=\ln (u)+\ln \left(V_{k}\right) \\
& +\ln \left(Y_{1}\right)+\ln \left(A_{i} * S_{j}\right)+e_{i j k l}
\end{aligned}
$$

The resulting index is shown in Fig. 2.

\section{The KGH, $0 \mathrm{~A}$ and inshore indices}

The analysis conducted for the $1 \mathrm{BCD}$ index was repeated for the $\mathrm{KGH}, 0 \mathrm{~A}$ and inshore indices, except there was no need to include an AREA effect in the $0 \mathrm{~A}$ index. A run of Model 2 showed that all the included interactions were significant but only had some minor explanatory value of the data (Table 2). For the KGH index the AREA main effect was not significant.

Based on similar arguments as for the development of the 1BCD index, the final models for the $\mathrm{KGH}$ and $\mathrm{OA}$ indices was reduced to a version of Model 1 without an AREA effect (Table 3). For the inshore index the significance of the interactions was driven by the 1995 abnormal year and the changes in the seasonal pattern in parallel to the behaviour of the index for the offshore areas Div. 1 BCD. The final model for the inshore index was therefore similar to Model 3. The resulting indices are shown in Fig. 2.

\section{Combined index 1976-97 for shrimp in Davis Strait}

The four indices are shown in last panel of Fig. 2 scaled by the estimated fleet factor, $v_{i}$. The indices are in reasonable agreement but show some divergence in most recent years. A correlation analysis (Table 4) indicates significant positive correlations between the overlapping data points of all pairs of CPUE indices except for the 1BCD-inshore time series. The combined index is shown in Fig. 3.

The combined index is expressed in relative CPUE units. Therefore, the total catch divided by the combined index provides an index of total effort in standardized units and this is shown in Fig. 4 that also shows the catches. The standardized effort increased drastically after 1988 and the CPUE index responded with a decline as would be expected from single species fish stock assessment models, e.g. Beverton and Holt (1957). 
TABLE 2. ANOVA schemes (type I ss) from the runs of Model 2 and from the final models of the four CPUE series (only statistically significant effects at $p=0.05$ are shown). The effects were entered in the models in order of decreasing type III mean ss.

\begin{tabular}{|c|c|c|c|c|c|c|c|c|c|c|}
\hline \multirow[b]{2}{*}{ Source } & \multicolumn{5}{|c|}{ Model 2} & \multicolumn{5}{|c|}{ Final model } \\
\hline & $\mathrm{df}$ & ss & $\mathrm{mss}$ & $\mathrm{F}$ & $\mathrm{r}^{2}$ & $\mathrm{df}$ & ss & $\mathrm{mss}$ & $\mathrm{F}$ & $\mathrm{r}^{2}$ \\
\hline \multicolumn{11}{|l|}{ 1BCD index } \\
\hline Total & 6094 & 36320 & & & & 6094 & 36320 & & & \\
\hline Error & 5878 & 15795 & 2.7 & & & 6056 & 19116 & 3.2 & & \\
\hline Model & 216 & 20524 & 95.0 & 35.36 & 0.57 & 38 & 17204 & 452.7 & 143.4 & 0.47 \\
\hline Vessel & 15 & 13421 & 894.7 & 333 & & 15 & 13420 & 894.7 & 283.5 & \\
\hline Area & 1 & 83 & 82.6 & 30.7 & & & & & & \\
\hline Month & 6 & 1268 & 211.3 & 78.6 & & & & & & \\
\hline Year & 10 & 2156 & 215.6 & 80.2 & & 10 & 2363 & 236.3 & 74.9 & \\
\hline Month*Area & 6 & 278 & 46.3 & 17.2 & & 13 & 1420 & 109.2 & 34.6 & \\
\hline Year*Month & 60 & 1857 & 30.9 & 11.5 & & & & & & \\
\hline Year*Area & 10 & 107 & 10.7 & 4 & & & & & & \\
\hline Year*Vessel & 108 & 1357 & 12.6 & 4.7 & & & & & & \\
\hline \multicolumn{11}{|l|}{ KGH index } \\
\hline Total & 1370 & 5994 & & & & 1370 & 5994 & & & \\
\hline Error & 1201 & 1773 & 1.5 & & & 1346 & 3034 & 2.3 & & \\
\hline Model & 169 & 4221 & 25.0 & 16.9 & 0.70 & 24 & 2930 & 123.3 & 54.7 & 0.49 \\
\hline Vessel & 1 & 265 & 265.3 & 179.6 & & 1 & 265 & 265.3 & 117.7 & \\
\hline Month & 9 & 2028 & 225.4 & 152.6 & & 9 & 2028 & 225.4 & 100.0 & \\
\hline Year & 14 & 666 & 47.6 & 32.2 & & 14 & 666 & 47.6 & 21.1 & \\
\hline Year*Vessel & 12 & 133 & 11.1 & 7.5 & & & & & & \\
\hline Year*Area & 14 & 317 & 22.6 & 15.3 & & & & & & \\
\hline Year*Month & 110 & 765 & 7.0 & 4.7 & & & & & & \\
\hline Month*Area & 9 & 46 & 5.1 & 3.5 & & & & & & \\
\hline \multicolumn{11}{|l|}{ OA index } \\
\hline Total & 514 & 4841 & & & & 514 & 4841 & & & \\
\hline Error & 421 & 1219 & 2.9 & & & 489 & 1726 & 3.5 & & \\
\hline Model & 93 & 3622 & 38.9 & 13.5 & 0.75 & 25 & 3115 & 124.6 & 35.3 & 0.64 \\
\hline Month & 1 & 336 & 336.1 & 116.1 & & 1 & 336 & 336.1 & 95.2 & \\
\hline Vessel & 9 & 1881 & 209.1 & 72.2 & & 9 & 1881 & 209.1 & 59.2 & \\
\hline Year & 15 & 897 & 59.8 & 20.7 & & 15 & 897 & 59.8 & 16.9 & \\
\hline Year*Month & 15 & 127 & 8.4 & 2.9 & & & & & & \\
\hline Year*Vessel & 53 & 381 & 7.2 & 2.5 & & & & & & \\
\hline \multicolumn{11}{|l|}{ Inshore index } \\
\hline Total & 1854 & 6487 & & & & 1854 & 6487 & & & \\
\hline Error & 1698 & 2497 & 1.5 & & & 1822 & 3442 & 1.9 & & \\
\hline Model & 156 & 3990 & 25.6 & 17.4 & 0.62 & 32 & 3045 & 95.2 & 50.4 & 0.47 \\
\hline Area & 2 & 650 & 325.0 & 221.1 & & & & & & \\
\hline Vessel & 9 & 1208 & 134.2 & 91.3 & & 9 & 989 & 109.8 & 58.2 & \\
\hline Month & 4 & 608 & 152.1 & 103.5 & & & & & & \\
\hline Area*Month & 8 & 117 & 14.6 & 10.0 & & 14 & 1595 & 113.9 & 60.3 & \\
\hline Year & 9 & 462 & 51.3 & 34.9 & & 9 & 462 & 51.3 & 27.2 & \\
\hline Year*Area & 18 & 253 & 14.0 & 9.5 & & & & & & \\
\hline Year*Month & 35 & 390 & 11.1 & 7.6 & & & & & & \\
\hline Year*Vessel & 71 & 303 & 4.3 & 2.9 & & & & & & \\
\hline
\end{tabular}



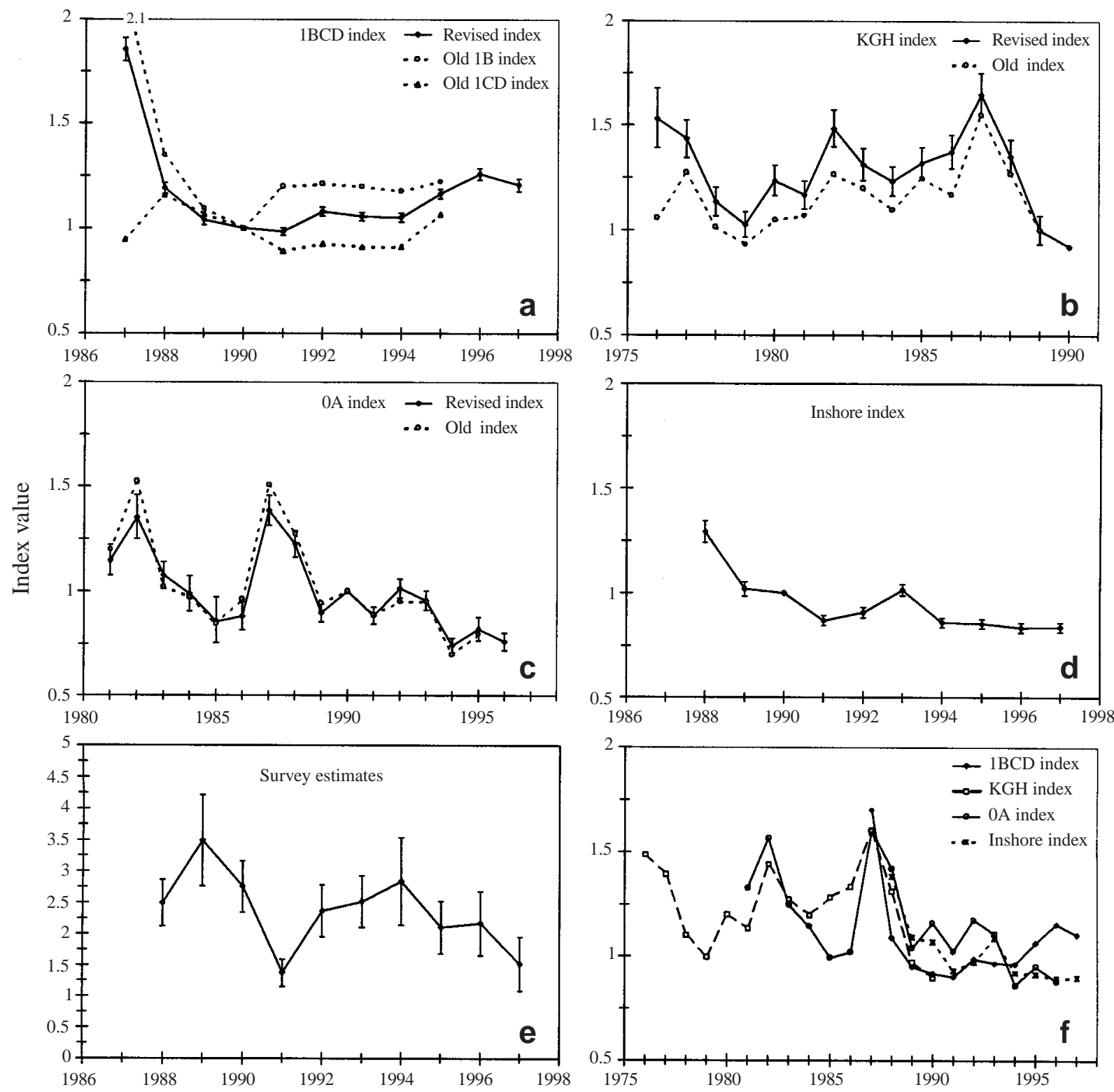

Fig. 2. Time series of the $1 \mathrm{BCD}(\mathbf{a}), \mathrm{KGH}(\mathbf{b})$ and $0 \mathrm{~A}(\mathbf{c})$ indices (revised and old versions), the new inshore (d) index and the research survey biomass (e) index ( \pm 1 standard error), and (f) shows individual indices scaled by the fleet factor, $v_{i}$, (see text). Old versions CPUE of indices are from Siegstad et al., MS 1995; Parsons and Veitch, MS 1995; Lassen and Carlsson, MS 1990. Survey indices calculated from Carlsson et al., MS 1998.

\section{Discussion}

Four different fleets largely fishing in different areas and over different periods (Table 1) supply the CPUE data on the West Greenland shrimp stock. Analyzing all data in a single model was not suitable. Such a model would have been highly unbalanced with a preponderance of empty cells, especially the ones tying the fleets together in time and space and therefore creating difficulty in separating area or year effects from vessel effects. We therefore developed separate indices by fleet before integrating them in one combined index.

All fleets included in the analysis mainly exploit shrimp greater than $17 \mathrm{~mm}$ carapace length. The CPUE indices are therefore indicative of the older male and the female stock combined. The 
TABLE 3. Time series of the four individual CPUE indices (1BCD, KGH, 0A and inshore) with standard errors (se) estimated by the GLM run of the final models and the combined CPUE index with jackknife estimated standard errors and Greenland research survey biomass estimates with standard errors from Carlsson et al. (MS 1998).

\begin{tabular}{|c|c|c|c|c|c|c|c|c|c|c|c|c|}
\hline \multirow[b]{2}{*}{ Year } & \multicolumn{2}{|c|}{$1 \mathrm{BCD}$} & \multicolumn{2}{|c|}{$\mathrm{KGH}$} & \multicolumn{2}{|c|}{$0 \mathrm{~A}$} & \multicolumn{2}{|c|}{ Inshore } & \multicolumn{2}{|c|}{ Combined } & \multicolumn{2}{|c|}{ Survey } \\
\hline & $\overline{\hat{X}}$ & $\overline{\mathrm{se}}$ & $\hat{X}$ & $\mathrm{se}$ & $\hat{X}$ & $\mathrm{se}$ & $\hat{X}$ & $\mathrm{se}$ & $\hat{X}$ & $\mathrm{se}$ & $\overline{\hat{X}}$ & $\mathrm{se}$ \\
\hline 1976 & - & - & 1.66 & 0.14 & - & - & - & - & 1.48 & 0.07 & - & - \\
\hline 1977 & - & - & 1.56 & 0.09 & - & - & - & - & 1.39 & 0.06 & - & - \\
\hline 1978 & - & - & 1.23 & 0.07 & - & - & - & - & 1.10 & 0.05 & - & - \\
\hline 1979 & - & - & 1.11 & 0.06 & - & - & - & - & 0.99 & 0.04 & - & - \\
\hline 1980 & - & - & 1.34 & 0.07 & - & - & - & - & 1.20 & 0.11 & - & - \\
\hline 1981 & - & - & 1.27 & 0.07 & 1.15 & 0.07 & - & - & 1.15 & 0.12 & - & - \\
\hline 1982 & - & - & 1.61 & 0.09 & 1.35 & 0.10 & - & - & 1.45 & 0.08 & & - \\
\hline 1983 & - & - & 1.42 & 0.08 & 1.08 & 0.06 & - & - & 1.27 & 0.07 & - & - \\
\hline 1984 & - & - & 1.34 & 0.07 & 0.99 & 0.08 & - & - & 1.19 & 0.51 & - & - \\
\hline 1985 & - & - & 1.43 & 0.07 & 0.86 & 0.11 & - & - & 1.25 & 0.05 & - & - \\
\hline 1986 & - & - & 1.49 & 0.08 & 0.88 & 0.07 & - & - & 1.30 & 0.05 & - & - \\
\hline 1987 & 1.86 & 0.06 & 1.79 & 0.10 & 1.38 & 0.07 & - & - & 1.65 & 0.06 & - & - \\
\hline 1988 & 1.19 & 0.03 & 1.47 & 0.08 & 1.22 & 0.06 & 1.29 & 0.05 & 1.22 & 0.03 & 2.49 & 0.37 \\
\hline 1989 & 1.04 & 0.02 & 1.09 & 0.07 & 0.90 & 0.04 & 1.02 & 0.03 & 0.98 & 0.02 & 3.48 & 0.73 \\
\hline 1990 & 1.00 & - & 1.00 & - & 1.00 & - & 1.00 & - & 0.93 & 0.03 & 2.75 & 0.41 \\
\hline 1991 & 0.98 & 0.02 & - & - & 0.88 & 0.04 & 0.87 & 0.02 & 0.92 & 0.02 & 1.37 & 0.22 \\
\hline 1992 & 1.08 & 0.02 & - & - & 1.01 & 0.05 & 0.91 & 0.02 & 1.00 & 0.03 & 2.36 & 0.42 \\
\hline 1993 & 1.05 & 0.02 & - & - & 0.96 & 0.05 & 1.02 & 0.03 & 1.00 & 0.03 & 2.51 & 0.41 \\
\hline 1994 & 1.05 & 0.02 & - & - & 0.74 & 0.03 & 0.86 & 0.02 & 0.95 & 0.03 & 2.83 & 0.70 \\
\hline 1995 & 1.16 & 0.02 & - & - & 0.82 & 0.05 & 0.85 & 0.02 & 1.04 & 0.29 & 2.10 & 0.42 \\
\hline 1996 & 1.26 & 0.03 & - & - & 0.76 & 0.04 & 0.84 & 0.02 & 1.10 & 0.03 & 2.17 & 0.51 \\
\hline 1997 & 1.21 & 0.03 & - & - & - & - & 0.84 & 0.02 & 1.07 & 0.03 & 1.52 & 0.43 \\
\hline
\end{tabular}

TABLE 4. Pearson product moment correlations $(r)$ between the CPUE and research survey indices. Values of $r$ significantly different from zero $(p<0.1$ on a 1 -tailed test) are marked with an asterisk.

\begin{tabular}{lccccc}
\hline \hline & KGH & 0A & Inshore & Survey & Comb. \\
\hline 1BCD & $0.93^{*}$ & $0.67^{*}$ & -0.03 & -0.14 & $0.98^{*}$ \\
KGH & & $0.61^{*}$ & $0.99^{*}$ & -0.46 & $0.97^{*}$ \\
OA & & & $0.88^{*}$ & 0.10 & $0.70^{*}$ \\
Inshore & & & & 0.36 & $0.49^{*}$ \\
Survey & & & & & -0.01 \\
\hline
\end{tabular}

derived combined index (Fig. 3) may be interpreted as fluctuations of this stock component by a factor of 2 around a constant level between 1976 and 1987 followed by a drop to a lower level in the late1980s. The marked spike in 1987 is likely the result of some very strong year-classes produced in the early-1980s (Anon., 1991). As stated 1995 was an abnormal year, which might explain the large

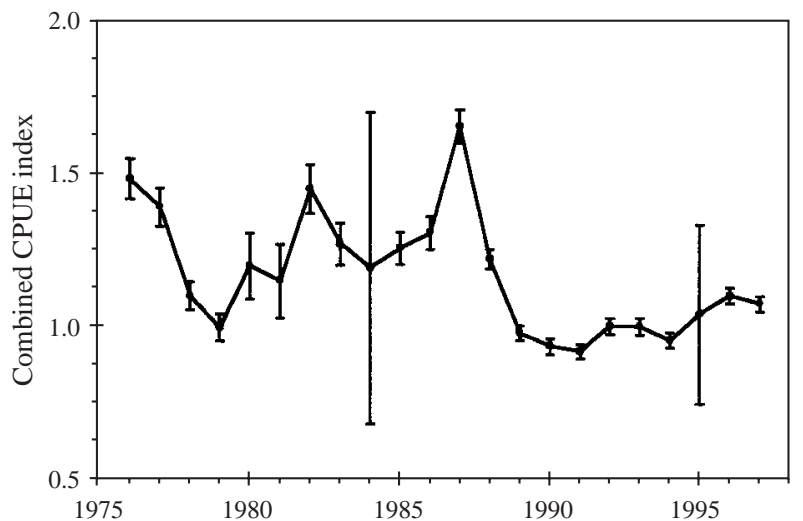

Fig. 3. Combined CPUE index for the Davis Strait shrimp stock 1976-97 ( \pm 1 standard error estimated by jackknifing).

standard error for the 1995 index. However, the reasons for the uncertainty in the 1984 estimate are unclear and require further investigation. 


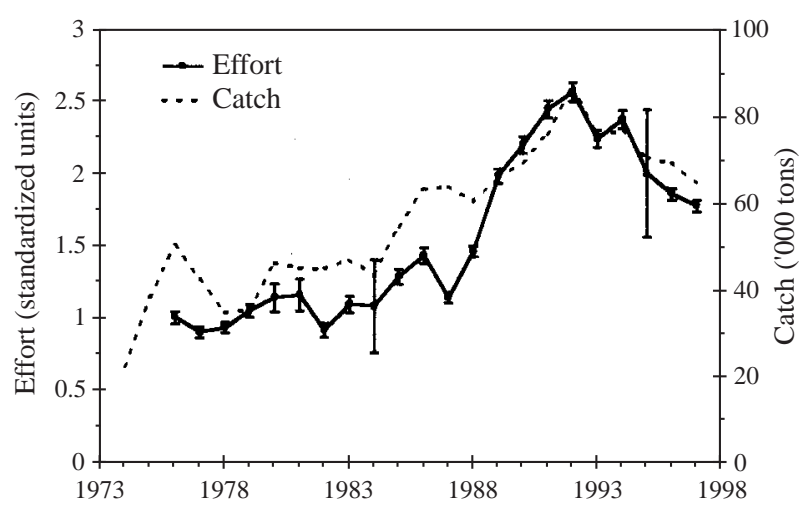

Fig. 4. Total catches 1974-97 (1 000 tons) and standardized effort, 1976-97 ( \pm 1 standard error) in Subareas 0 and 1.

CPUE indices reflect stock biomass but there may not be direct proportionality. The relation depends in part on the response in fishing strategy to abundance changes (Hilborn and Walters, 1992). The use of CPUE indices as biomass indicators should therefore be evaluated, e.g. using survey results. Research survey data are available for JulyAugust during 1988-97 (Carlsson et al., MS 1998). A correlation analysis (Table 4) indicated no correlation between the overlapping data points of the survey and either of the CPUE indices implying that they are not measuring the same thing. However, the period of comparison is one of relative stable CPUE indices and survey estimates fluctuating around its mean (Table 3 ). A comparison of the variance between the yearly survey biomass estimates and the variance of estimate accuracy revealed that the signal to noise ratio in the survey series is smaller than one. In this case the fact that the CPUE indices and the survey estimates actually do agree very well in their overall trend renders the correlation analysis a weak test as a very low correlation between two such data sets is to be expected.

The use of a CPUE index as a biomass indicator assumes that the efficiency of the fleet does not change over time. Efficiency increases in a fishing fleet can result from introduction of new and more efficient fishing vessels, withdrawal of older vessels and increased efficiency of existing vessels. Increases in fleet efficiency can be substantial. For the US Pacific coast groundfish trawl fishery (1982-89) the increase in fishing power has been estimated as almost 3\% per year (Squires, 1994). Daan et al. (1994) estimated an increase of $4 \%$ per year in the efficiency of the North Sea cod fishery, 1963-73.
Trawls in the Greenlandic shrimp fishery during 1976-97 became much larger. While a standard shrimp trawl in the mid-1970s had an opening of approximately 1600 meshes, trawls of today are often more than 4000 meshes. New technology has also caused jumps in efficiency. Around 1980 more efficient gear was adopted (new trawl type and bottom gear) and in 1985-86 high opening trawls with KEVLAR netting and trawl positioning systems were introduced (Carlsson and Kanneworff, MS 1987). The introduction of an ITQ system in the Greenlandic offshore shrimp fishery in 1991 brought about a significant restructuring of the harvesting sector and may have increased the efficiency of the remaining fleet. The introduction of better navigation equipment in the beginning of the 1990s and trawls with reduced water resistance (i.e. less drag) in late-1990s probably also have increased vessel efficiency. Although there is no information on whether similar changes took place at the same time in the Canadian shrimp fishery in Div. 0A, it is likely given the proximity of the fisheries.

Our analysis accounts for increases in efficiency from renewal of the fleet by including a vessel factor, but assumes constant efficiency over time of individual vessels. The YEAR*VESSEL term can be a random effect e.g. originating from a vessel having a lucky season or it can be caused by a vessel being upgraded before or after the rest of the fleet. This thus indicates the problem of the continuing effect of improved fishing power. However, the lack of importance of the YEAR*VESSEL term suggests that efficiency increases of single vessels compared to the total fleet had minor influence on the CPUE index.

In total all interactions including VESSEL explained less than $5 \%$ of the total variation even though they introduced a large number of parameters. There was no prior reason to suppose that vessels should show different efficiency in different months (VESSEL*MONTH interaction). The VESSEL*AREA interaction also did not plausibly correspond to reality as the vessels involved in the fishery are highly mobile, fish in all areas and to a large extent share information (common ownership). Therefore interactions including VESSEL were omitted from further investigations.

The major concern in the analyses is the presence of interactions with YEAR. Such interactions may indicate violation of the basic assumptions 
mentioned under the Material and Methods section and the estimated YEAR effect may in this situation not be used as the biomass index sought (Anon., 1993). Our analysis is potentially confounded due to a relatively large number of empty cells. It is therefore difficult to account precisely for the cause of the interactions. The interactions found by the analysis may result from unsystematic changes in seasonality and area distribution between years and this would add to the variance of the CPUE indices but not introduce bias in the time trend.

Variation in CPUE data is typically high and for that reason the analyses was done on cell averages. This approach was chosen to improve the signal-to-noise ratio. The calculations were repeated based on individual haul information and this did not change the annual abundance indices appreciably but the $\mathrm{R}^{2}$ was only about $10 \%$ making it difficult to investigate the model structure. We weighted the data to prevent inordinate influence of a few hauls on the model. Number of hauls was used as the weighting factor as it is proportional to the variance of the mean $\ln (\mathrm{CPUE})$ in a cell.

The YEAR*AREA interaction was found to be caused by apparently random shifts in good and bad fishing areas between years and may be influenced by changes in the shrimp fishery in the period 198797. The fishery occurred mainly in NAFO Div. 1A$1 \mathrm{C}$ up to 1987 but expanded gradually to include more southerly grounds thereafter. In 1995 the shrimp fishery operated in all Divisions in Subarea 1. (Hvingel, MS 1996). The expansion of the fishery may have occurred because technological improvements allowed access to new grounds. However, results from Greenlandic research surveys suggest that the observed changes in effort distribution reflect a southward shift of biomass (Carlsson and Kanneworff, MS 1997).

The YEAR*MONTH interaction reflects variation in the environment, e.g. ice coverage. The timing of seasonal changes in the environment varies between years, and the analysis could be refined if data on an environmental indicator of stock distribution were available. Such biophysical or oceanographic markers have yet to be identified.

The final models for the $1 \mathrm{BCD}$ and inshore indices include the second order effect AREA* MONTH. This means that the availability of shrimp does not show a geographically constant pattern throughout the year. This could be a result of changes in shrimp behaviour with size combined with an uneven geographical distribution of sizes or a seasonal migration pattern (Parsons et al., MS 1991). Seasonal migrations of shrimp in inshore West Greenland waters have been proposed by Horsted and Smidt (1956). They found that changes in distribution in some fjords were correlated with bottom water temperature. Migration of berried females into shallower water was also observed. Seasonal migration in the offshore areas has not been demonstrated.

Despite the presence of interactions with year (which were thoroughly investigated), the main effects due to years were robust. Tested by jackknifing the data using years as observational units, the year effects did not change much when data for individual years were deleted from the model. However, the combined CPUE index gives an optimistic view of the trend in biomass because individual ships in this fishery have become more efficient with time, and this model does not try to account for such changes. We recommend further investigation of this effect.

\section{Acknowledgements}

We thank Dan M. Carlsson, and Ole Folmer at the Greenland Institute of Natural Resources and Patrick J. Veitch, Department of Fisheries and Oceans, St. John's, Newfoundland, for their input to this study at the meeting of shrimp experts in St. John's, Newfoundland, in 1996. We thank Anne Richards, Steven X. Cadrin and an anonymous referee for comments on an earlier version of the paper, comments that helped improving the analysis and the presentation. A final note of thanks goes to Michael C. S. Kingsley for constructive comments and recommending the method for combining indices.

\section{References}

ANON. 1988. SAS/STAT User's Guide, Release 6.03 Edition. Cary, NC: SAS Institute Inc., 1988, 1028 p. 1991. NAFO Sci. Coun. Rep., 1991, 166 p. 1993. Reports of the Working Group on Methods of Fish Stock Assessments. Copenhagen, 9-16 June 1987; Reykjavik, 6-12 July 1988; Nantes, 1017 November 1989. ICES Coop. Res. Rep., No. 191, $249 \mathrm{p}$.

1997. NAFO Sci. Coun. Rep., 1996, 226 p.

BEVERTON, R. J. H., and S. J. HOLT. 1957. On the dynamics of exploited fish populations. MAFF Lon- 
don. Series 2. 19(12): 172-178.

CARLSSON, D. M. MS 1985. Data on the Shrimp Fishery in NAFO Subarea 1 in 1983 and 1984. NAFO SCR Doc., No. 3, Serial No. N937, 45 p.

CARLSSON, D. M., and P. KANNEWORFF. MS 1987. The Shrimp Fishery in NAFO Subarea 1 in 1985 and 1986. NAFO SCR Doc., No. 8, Serial No. N1276, $32 \mathrm{p}$.

CARLSSON, D. M., and P. KANNEWORFF. MS 1997. Offshore stratified-random trawl survey for shrimp (Pandalus borealis) in NAFO Subarea 0+1, in 1997. NAFO SCR Doc., No. 101, Serial No. N2958, 19 p.

CARLSSON, D. M., and H. LASSEN. MS 1991. A catchrate index for large shrimp in the Greenland shrimp fishery in NAFO Division 1B. NAFO SCR Doc., No. 57, Serial No. N1914, 14 p.

CARLSSON, D. M., P. KANNEWORFF, and H. SIEGSTAD. MS 1993. The shrimp fishery in NAFO Subarea 1 January to October 1993. NAFO SCR Doc., No. 93, Serial No. N2340, 29 p.

CARLSSON, D. M., O. FOLMER, C. HVINGEL, P. KANNEWORFF, M. PENNINGTON, and H. SIEGSTAD. MS 1998. A review of the trawl survey of the shrimp stock off West Greenland. NAFO SCR Doc., No. 114, Serial No. N4023, 21 p.

DAAN, N., H. J. L. HEESSEN, and J. G. POPE. 1994. Changes in the North Sea cod stock during the twentieth century. ICES Mar. Sci. Symp., 198: 229-243.

EFRON, B. 1982. The jackknife, the bootstrap, and other resampling plans. Soc. for Indust. and App. Math. Philadelphia, Pa. 92 p.

GAVARIS, S. 1980. Use of a multiplicative model to estimate catch rate and effort from commercial data. Can. J. Fish. Aquat. Sci., 37: 2272-2275.

GASIUKOV, P. S. 1991. Standardization of fishing effort for Champsocephalus gunnari in the South Georgia area (Subarea 48.3). Selected scientific papers 1990. Hobart Australia CCAMLR: 327-336.

GULLAND, J. A. 1956. On the fishing effort in English dermersal fisheries. Fish. Invest. MAFF London. Series 2, 20(5): 1-41.

HILBORN, R., and C. J. WALTERS. 1992. Quantitative fisheries stock assessment. Capman and Hall New York, $570 \mathrm{p}$.

HOEY, J. J., J. MEJUTO, J. M. PORTER, H. H. STONR, and Y. UOZUMI. 1995. An updated biomass index of abundance for North Atlantic swordfish, 19631993. Collect. Vol. Sci. Pap. ICCAT-RECL. Doc. Sci. CICTA-COLLEC. Doc. Cient. CICAA, 44, No 3: 187-196.

HORSTED, S. A., and E. SMIDT. 1956. The deep sea prawn (Pandalus borealis Kr.) in Greenland waters. Medd. Dan. Fisk. Havunders., N.S. 1(11), 118 p.

HVINGEL, C. MS 1996. Geographical changes in the fishing pattern of Greenlandic shrimp trawlers in the Davis Strait, 1987-1996. NAFO SCR Doc., No. 110, Serial No. N2807, 5 p.
KIMURA, D. K. 1981. Standardized measures of relative abundance based on modelling $\log$ (c.p.u.e.), and their application to Pacific ocean perch (Sebastes alutus). ICES J. Cons., 39: 211-218.

LARGE, P. A. 1992. Use of a multiplicative model to estimate relative abundance from commercial CPUE data. ICES J. Mar Sci., 49: 253-261.

LASSEN, H., and D. M. CARLSSON. MS 1990. A catchrate index for the Greenland shrimp fishery in NAFO Subarea 1. NAFO SCR Doc., No. 90, Serial No. N817, 14 p.

LEHMANN, K. M., and H. DEGEL. MS 1991. An estimate of shrimp discard from shrimp factory trawlers in Davis Strait and Denmark Strait. NAFO SCR. Doc., No. 40, Serial. No. N1920, 11 p.

MIYAKI, N. 1989. Standardized CPUE for the Atlantic swordfish caught by Japanese longline fishery. Collect. Vol. Sci. Pap. ICCAT-RECL. Doc. Sci. CICTACOLLEC. Doc. Cient. CICA, 32, No 2: 371-376.

PARSONS, D. G., R. E. CRAWFORD, L. SAVARD, and E. L. DALLEY. MS 1991. Aspects of the distribution and behaviour of northern shrimp (Pandalus borealis) affecting survey design and stock assessment. ICES C.M. Doc., No. K42: 10 p.

PARSONS, D. G., and P. J. VEITCH. MS 1991. The Canadian fishery for Northern Shrimp (Pandalus borealis) in Division 0A, 1990. NAFO SCR Doc., No. 33, Serial No. N1913, 27 p.

MS 1995. The Canadian fishery for Northern Shrimp (Pandalus borealis) in Division OA and Subarea 1, 1979-1995. NAFO SCR Doc., No. 107, Serial No. N2646, 17 p.

PASCOE, S., and C. ROBINSON. 1996. Measuring changes in technical efficiency over time using catch and stock information. Fish. Res., 28: 305-319.

PERODOU, J. B. 1994. Exploited southern red snapper's population dynamics (Lutjanus purpureus) in French Guiana. Complementary point of view of global and structural analysis. Lille-France Univ. Sci. Tech. Lille, 1994, 262 p.

PERODOU, J. B., and E. PREVOST. 1989. The fishery of the southern red snapper (Lutjanus purpureus) in French Guiana: Analysis and processing of fishery statistics. Bol. Inst. Oceanogr. Venez., 28, No. 1-2: 253-261.

RICHARDS, L. J., and J. T. SCHNUTE. 1992. Statistical models for estimating CPUE form catch and effort data. Can. J. Fish. Aquat. Sci., 49: 1315-1327.

ROBSON, D. S. 1966. Estimation of the relative fishing of individual ships. ICNAF Res. Bull., 3: 5-14.

SIEGSTAD, H., C. HVINGEL, and O. FOLMER. MS 1995. The Greenland Fishery for Northern Shrimp (Pandalus borealis) in Davis Strait in 1994 and January-October 1995. NAFO SCR. Doc., No. 110, Serial No. N2649, 34 p.

SQUIRES, D. 1994. Sources of growth in marine fishing industries. Mar. Pol., 18(1): 5-18. 